\title{
PERANCANGAN MOBILE APPLICATION BERBASIS ANDROID UNTUK MENUNJANG KEMAMPUAN KOGNITIF DAN PSIKOMOTORIK SISWA PAUD
}

\author{
Aji Setiawan $^{[1]}$, Timor Setiyaningsih ${ }^{[2]}$, Triwibowo ${ }^{[3]}$ \\ Program Studi Teknik Informatika, Universitas Darma Persada ${ }^{[1][2][3]}$ \\ Jl. Raden Inten II, Kota Jakarta Timur, Kode Pos 13450, Jakarta, Indonesia \\ E-mail : aziesetiawan@gmail.com ${ }^{[1]}$,tiyaning@gmail.com ${ }^{[2]}$,cobracx372@gmail.com ${ }^{[3]}$
}

\begin{abstract}
Abstrak
Pendidikan Anak Usia Dini (PAUD) merupakan upaya pembinaan yang ditujukan kepada anak sejak lahir sampai dengan usia enam tahun yang dilakukan melalui pemberian stimulus pendidikan agar membantu perkembangan, baik jasmani maupun rohani sehingga anak memiliki kesiapan memasuki pendidikan yang lebih lanjut. Perkembangan fisik dan motorik anak akan dapat terpenuhi secara baik dan optimal ketika telah terbiasa dengan berbagai aktivitas bermain, bergerak secara bebas dan leluasa yang dilakukan di pendidikan usia dini. Sistem pembelajaran pengenalan hewan, buah, warna dan angka yang diajarkan di PAUD Kenanga terdapat keterbatasan dalam penyampaiannya, misal pengenalan dengan menggunakan buku atau poster-poster kecil untuk memperlihatkan jenis-jenis hewan dan buah yang jarang didapatkan disekitar sekolah. Atas permasalahan tersebut dirancang sebuah sistem informasi yang memberikan model pembelajaran yang menarik bagi siswa dengan membuat sebuah aplikasi mobile pengenalan hewan dan karakteristik hewan yang dilengkapi dengan animasi, gambar, dan suara agar anak pendidikan usia dini tertarik untuk belajar mengenal hewan dengan platform android SDK. Hasil pengujian sistem dan evaluasi ke pengguna berdasarkan kuesioner didapatkan hasil bahwa aplikasi dengan media smartphone yang telah dibangun dapat meningkatkan kemampuan kognitif dan psikomotorik siswa dengan adanya fitur bermain dan belajar.
\end{abstract}

Kata kunci : Aplikasi mobile, android SDK, PAUD, kognitif, psikomotorik.

\begin{abstract}
Pendidikan Anak Usia Dini (PAUD) is a coaching effort aimed at children from birth to six years which is carried out through provision of educational stimulus to help development, both physical and spiritual so children has ready to enter further education. Physical and motoric development of children will be fulfilled well and optimally when they are accustomed to a variety of playing activities, freely in early childhood education. Animal, fruit, color and number recognition in learning systems taught at Kenanga PAUD have limitations in delivery, for example introduction by using small books or posters to show the types of animals and fruits that are rarely found around schools. On this issue an information system is designed that provides an interesting learning model for students by creating a mobile application for animal recognition and animal characteristics that is equipped with animation, images, and sounds so that early childhood education is interested in learning about animals with the android SDK platform. The results of system testing and user evaluation based on questionnaire showed that smartphone app that had been built could improve students cognitive and psychomotor abilities with features of playing and learning.
\end{abstract}

Keywords : mobile application, android SDK, PAUD, cognitive, psychomotor. 


\section{Pendahuluan}

Pendidikan Anak Usia Dini merupakan upaya pembinaan yang ditujukan kepada anak sejak lahir sampai dengan usia enam tahun yang dilakukan melalui pemberian stimulus pendidikan agar membantu perkembangan, baik jasmani maupun rohani sehingga anak memiliki kesiapan memasuki pendidikan yang lebih lanjut. Metode pembelajaran dengan konsep praktikum dapat meningkatkan kemampuan kognitif dan psikomotorik siswa [1] dan faktor penggunaan smartphone dapat meningkatkan peran penggunaan pengguna terhadap suatu teknologi [2]. Kesiapan untuk memasuki sekolah bisa dilihat dari kesiapan anak ketika berada di pendidikan usia dini dan pra-sekolah. Perkembangan fisik dan motorik anak akan dapat terpenuhi secara baik dan optimal ketika mereka telah terbiasa dengan berbagai aktivitas bermain, bergerak secara bebas dan leluasa yang dilakukan di pendidikan usia dini. Bermain gerak yang memerlukan keterlibatan fisik dan motorik anak bisa dilakukan lewat model bermain menirukan perilaku binatang. Misalnya, bagaimana kucing berebut makan sesama kucing, kucing menangkap tikus, dan kucing berkelahi. Masih banyak lagi model-model bermain yang dapat mengembangkan kemampuan fisik dan motorik anak usia dini yang dilakukan di Pendidikan Anak Usia Dini (PAUD).

Pengenalan hewan, buah, warna dan angka merupakan salah satu pembelajaran yang dipelajari oleh siswa pendidikan usia dini di PAUD Kenanga. Materi ini membahas tentang pengenalan hewan, buah, warna dan angka mulai dari bentuk fisik hingga suara hewan. Sistem pembelajaran pengenalan hewan, buah, warna dan angka yang diajarkan guru PAUD Kenanga hanya menyampaikan pengenalan dengan menggunakan buku atau poster-poster kecil karena akses yang cukup jauh untuk memperlihatkan jenis-jenis hewan dan buah yang jarang didapatkan disekitar sekolah. Guru harus membawa siswa ke kebun binatang atau taman buah untuk menyampaikan materi pengenalan suara hewan, sehingga siswa kurang mengerti karena model pembelajaran seperti ini guru hanya menunjukkan gambar dan menirukan suara dari masing-masing hewan tersebut.

Dari hasil wawancara kepada guru PAUD Kenanga, ternyata cara pembelajaran seperti ini memiliki beberapa kelemahan yaitu, siswa yang sedang belajar di kelas kadang tidak fokus pada materi yang sedang diajarkan karena minimnya interaksi siswa terhadap materi dan juga kurang jelasnya pengenalan hewan secara langsung sehingga siswa kurang jelas untuk mengetahui bentuk fisik dari masing-masing hewan tersebut. Setelah penulis melakukan pengamatan diketahui bahwa dari 32 siswa/i Pendidikan Anak Usia Dini (PAUD) Kenanga, kelompok belajar usia lima sampai enam tahun masih terdapat siswa/i yang mempunyai nilai tingkat pencapaian perkembangan anak yang dibawah ketentuan dari pihak PAUD Kenanga. Oleh karena itu guru membutuhkan bantuan media pembelajaran, salah satunya dengan aplikasi pembelajaran berbasis multimedia dengan android, dimana guru dituntut untuk mengembangkan perangkat pembelajaran yang komprehensif yang salah satunya mencakup pengadaan media pembelajaran yang interaktif.

Berdasarkan latar belakang yang telah diuraikan maka kami mendapatkan kesimpulan dibutuhkan aplikasi yang bisa memberikan cara pembelajaran baru dan menarik dengan membuat sebuah aplikasi pengenalan hewan dan karakteristik hewan yang dilengkapi dengan animasi, gambar, dan suara agar anak pendidikan usia dini tertarik untuk belajar mengenal hewan. Dengan menyajikan menu belajar, menu pengenalan karakteristik, dan evaluasi soal dengan menebak gambar hewan sehingga aplikasi yang disajikan kepada anak usia dini lebih menarik dan interaktif. 


\section{Dasar teori}

Menurut [2] dalam penelitian yang telah dilakukan sebelumnya mengungkapkan bahwa faktor mobility dalam hal ini penggunaan media mobile seperti smartphone dapat meningkatkan peran penerimaan pengguna[2], atas latar belakang tersebut kami mencoba membangun aplikasi berbasis mobile untuk menunjang teori yang sudah didapat sebelumnya.

\subsection{Android SDK (Software Development Kit)}

Android SDK adalah tools API (Application Programming Interface) yang diperlukan untuk mulai mengembangkan aplikasi pada platform Android menggunakan bahasa pemrograman Java. Android merupakan subset perangkat lunak untuk ponsel yang meliputi sistem operasi, middleware dan aplikasi kunci yang di release oleh Google. Saat ini disediakan android SDK sebagai alat bantu dan API untuk mulai mengembangkan aplikasi pada platform Android menggunakan bahasa pemrograman java dan telah dilakukan beberapa percobaan pengujian dengan SDK untuk mengimplementasikan beberapa fitur perangkat Android, seperti (menjalankan google browser, menyambung ke internet, mengirim pesan, melihat informasi dasar perangkat (ruang memori, dan keamanan) fitur-fitur ini diimplementasikan menggunakan perangkat virtual GALAXY_NOT4_API_219 [3].

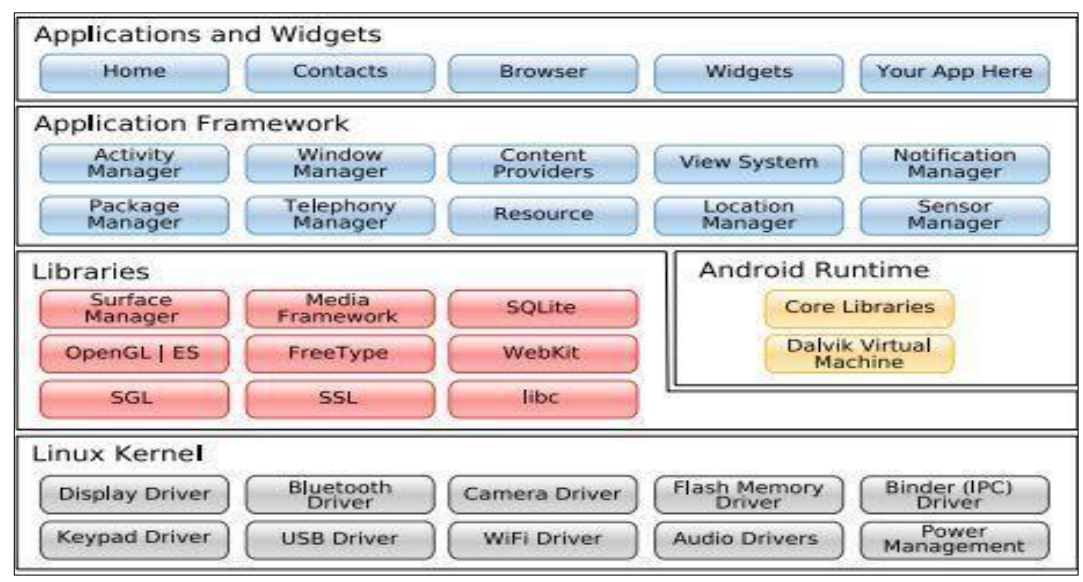

Gambar 1. Arsitektur Android.

\subsection{Kemampuan kognitif dan psikomotorik}

Kemampuan kognitif digambarkan dengan bagaimana fikiran anak dapat berkembang dan berfungsi, dapat diartikan dalam arti luas kemampuan kognitif segala sesuatu hal mengenai berfikir dan mengamati proses tersebut mendatangkan pengetahuan atau yang dibutuhkan untuk menggunakan pengetahuan. Banyak penelitian yang membahas masalah aspek kognitif khususnya bagi para pelajar salah satunya berkesimpulan bahwa dalam perkembangan sebuah bahasa terdapat pengaruh terhadap perkembangan kognitif anak usia 1-3 tahun. [4]

Sedangkan psikomotorik meliputi perilaku gerakan dan koordinasi jasmani, keterampilan motorik dan kemampuan fisik siswa, terdapat 7 kategori aspek psikomotorik salah satunya adalah peniruan. Peniruan ini yang menjadi landasan aplikasi ini dibangun tujuannya agar para siswa nantinya dapat mengikuti perilaku apa yang dicontohkan ibu pengajar misalnya dalam hal pengenalan nama-nama hewan. Berdasarkan penelitian yang telah dilakukan didapatkan kesimpulan bahwa dalam penerapan pembelajaran berbasis praktikum dapat meningkatkan kemampuan kognitif dan kemampuan psikomotorik siswa[1]. 


\section{Metodologi Penelitian}

Metodologi penelitian sangat diperlukan untuk memecahkan masalah dalam penelitian. Penelitian ini menggunakan metode deskriptif yaitu metode penelitian yang bertujuan untuk membuat deskripsi, gambaran atau lukisan secara sistematis, faktual dan akurat mengenai faktafakta, sifat serta hubungan antar fenomena yang diselidiki. dan untuk metode pengembangan perangkat lunak kami menggunakan metode SDLC Waterfall yang memiliki beberapa tahapan yang terdiri dari : (1) requirement (analisis kebutuhan), (2) system design, (3) coding \& testing (implementasi), (4) penerapan program (verifikasi), dan (5) maintenance[5].

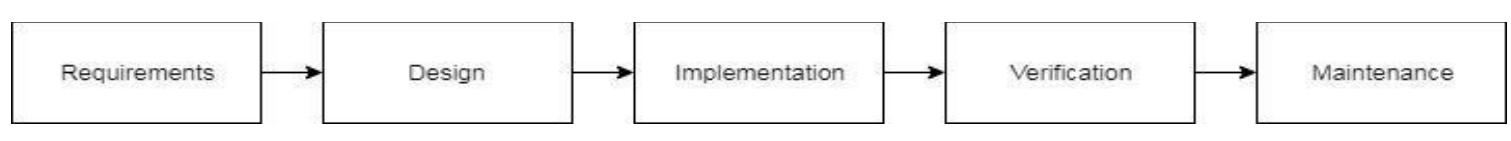

Gambar 2. Waterfall SDLC.

\section{Pengujian dan Pembahasan}

\subsection{Analisis sistem saat ini}

Dalam prakteknya pembelajaran pengenalan hewan, buah, warna dan angka yang diajarkan di PAUD Kenanga, para guru hanya menyampaikan pengenalan dengan menggunakan buku atau poster-poster kecil karena akses yang cukup jauh untuk memperlihatkan jenis-jenis hewan dan buah yang jarang didapatkan disekitar sekolah. Kami melakukan wawancara langsung kepada guru PAUD Kenanga, ternyata cara pembelajaran seperti ini memiliki beberapa kelemahan yaitu, siswa yang sedang belajar di kelas kadang tidak fokus pada materi yang sedang diajarkan karena minimnya interaksi siswa terhadap materi dan juga kurang jelasnya pengenalan hewan secara langsung sehingga siswa kurang jelas untuk mengetahui bentuk fisik dari masing-masing hewan tersebut. Setelah penulis melakukan pengamatan diketahui bahwa dari 32 siswa/i Pendidikan Anak Usia Dini (PAUD) Kenanga, Kelompok Belajar usia lima sampai enam tahun masih terdapat siswa/i yang mempunyai nilai tingkat pencapaian perkembangan anak yang dibawah ketentuan dari pihak PAUD Kenanga.

\subsection{Analisis sistem yang diusulkan}

Dalam penelitian sebelumnya implementasi teknologi yang bersifat publik didapatkan kesimpulan bahwa faktor mobility dalam penggunaan $e$-voting memiliki hubungan yang erat dengan tingkat penggunaan masyarakat terhadap sebuah teknologi [2]. Berdasarkan latar belakang yang telah diuraikan penulis mencoba memberikan cara pembelajaran baru dan menarik dengan membuat sebuah aplikasi mobile pengenalan hewan dan karakteristik hewan yang dilengkapi dengan animasi, gambar, dan suara agar siswa PAUD tertarik untuk belajar mengenal hewan, angka, dan huruf sehingga diharapkan kemampuan kognitif dan psikomotorik siswa dapat meningkat. Untuk itu sebagai bagian dari perencanaan, penulis melakukan perencanaan dengan menggunakan UML seperti use case, dan activity diagram. Untuk use case dapat kami gambarkan sebagai berikut : 


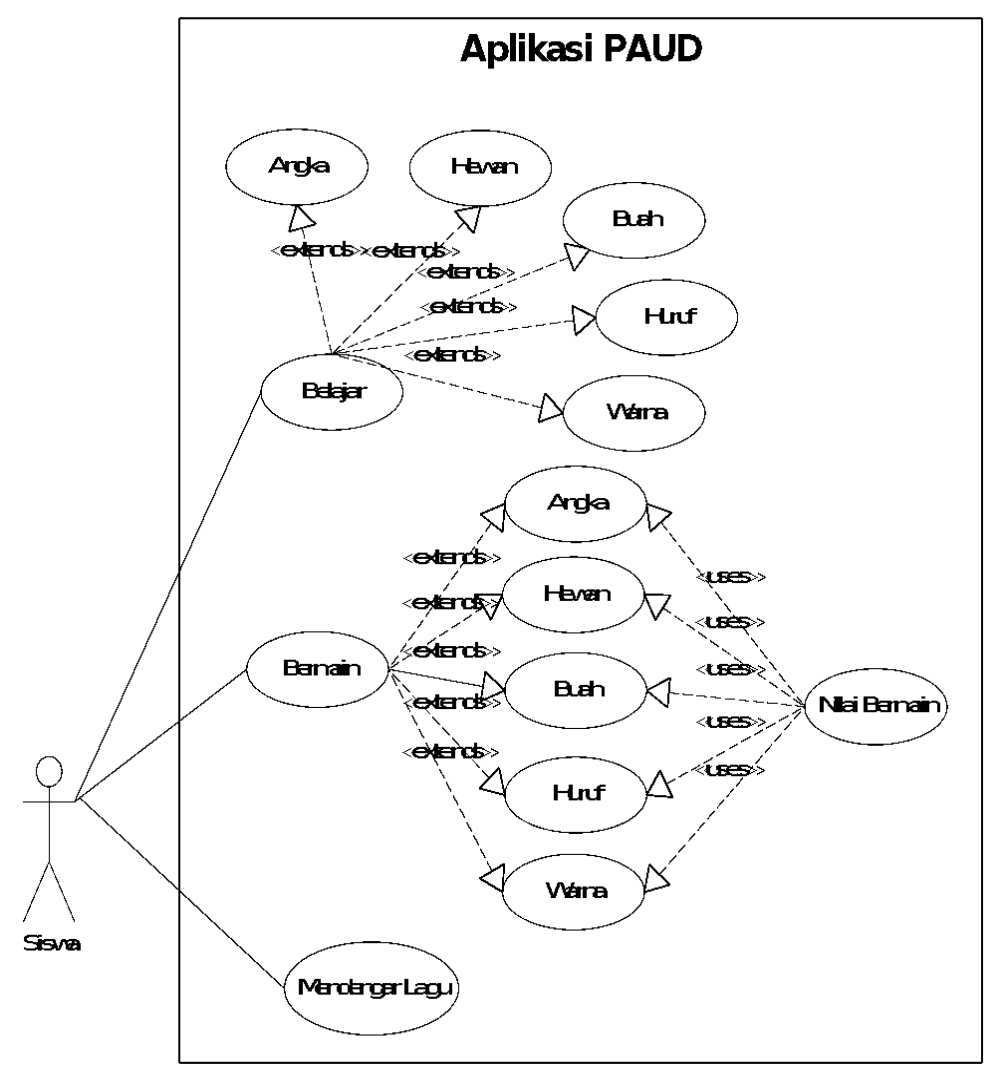

Gambar 3. Use case siswa.

Gambar 3 menjelaskan bahwa siswa secara garis besar dapat menggunakan aplikasi untuk memilih menu dari objek yang ditampilkan berupa menu belajar, bermain dan mendengarkan lagu.

\subsection{Activity Diagram}
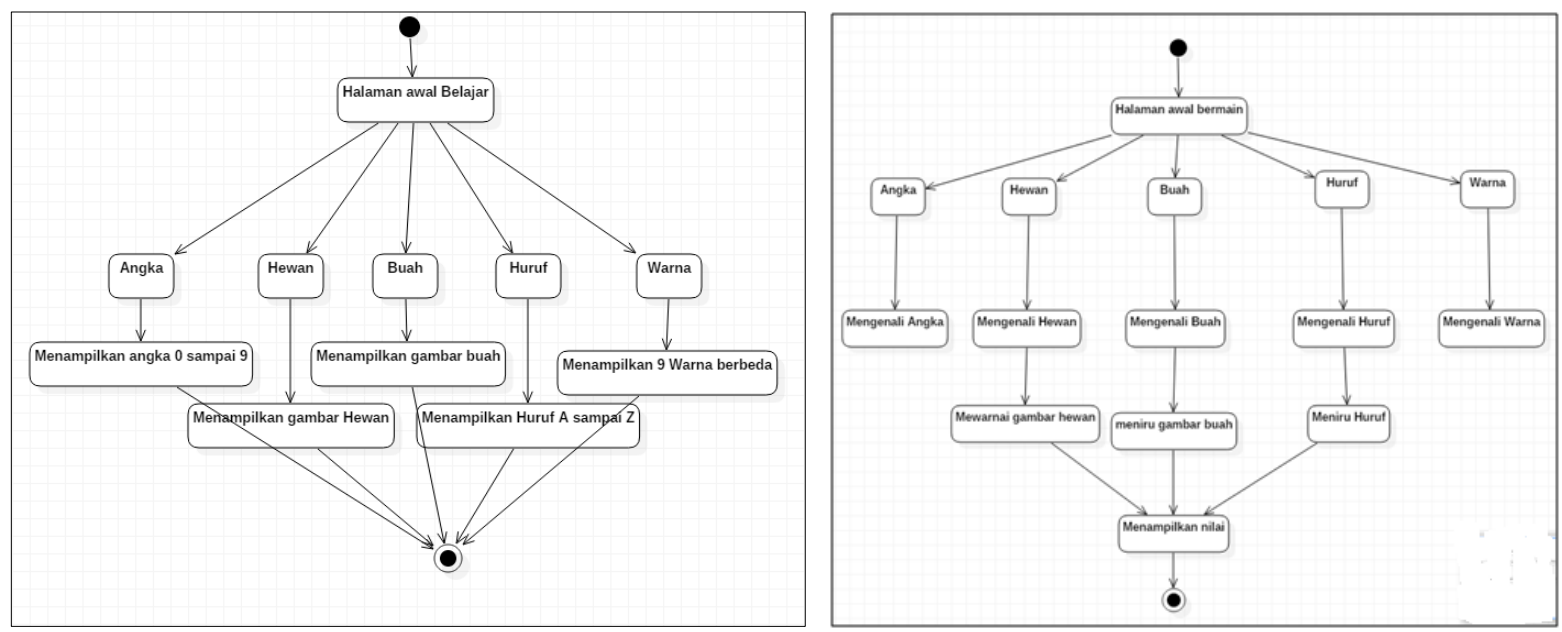

Gambar 4. Use case halaman belajar.

Gambar 5. Use case halaman bermain.

Dari activity diagram gambar 4, dapat dilihat aktivitas dari aplikasi game edukasi untuk anak usia dini, yaitu user membuka aplikasi lalu halaman belajar terus memilih kategori angka, 
hewan, huruf, buah dan warna, kemudian siswa dapat memilih kategori yang ingin dipelajari seperti menampilkan angka 0 sampai 9, menampilkan gambar hewan, buah, huruf a sampai z, dan menampilkan 9 warna yang berbeda. Selanjutnya pada gambar 5, para siswa juga dapat membuka aplikasi bermain melalui menu bermain, siswa bisa memilih bermain dengan kategori angka, hewan, huruf, buah, warna, mewarnai, meniru gambar buah dan meniru gambar huruf diakhir sesi bermain akan ditampilkan hasil akhir berupa nilai.

\subsection{Rancangan Tampilan Sistem}

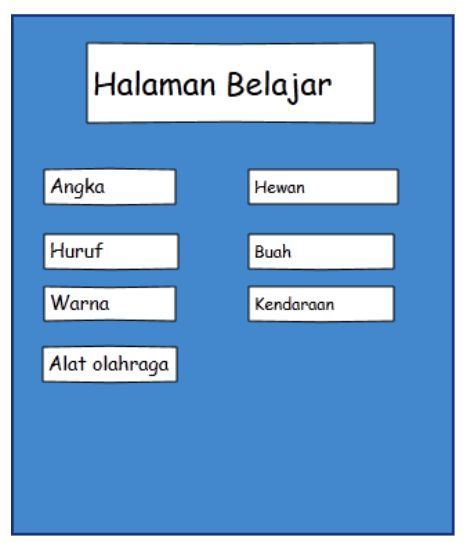

Gambar 6. Rancangan Halaman Belajar

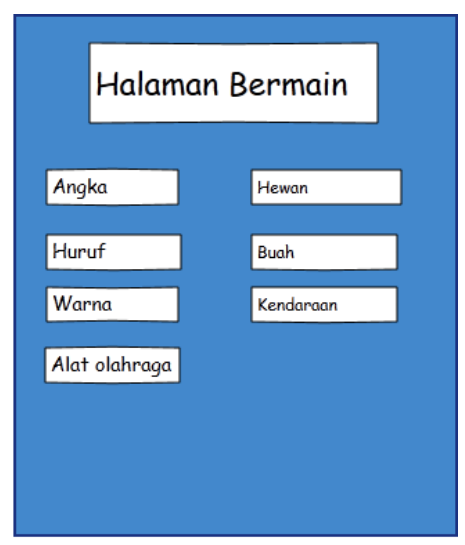

Gambar 7. Rancangan Halaman Bermain

Gambar 6 adalah halaman belajar, pada halaman ini disediakan beberapa pilihan pembelajaran seperti angka, huruf, buah, warna, alat olahraga, kendaraan dan hewan. Sedangkan pada gambar 7 halaman bermain disediakan sarana beberapa pilihan permainan angka, huruf, buah, warna, alat olahraga, kendaraan dan hewan.

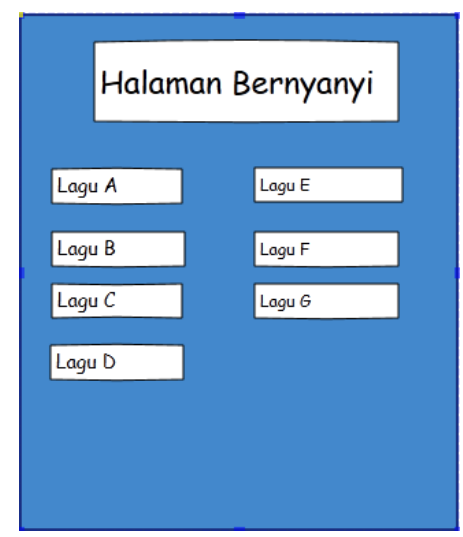

Gambar 8. Rancangan Halaman Bernyanyi

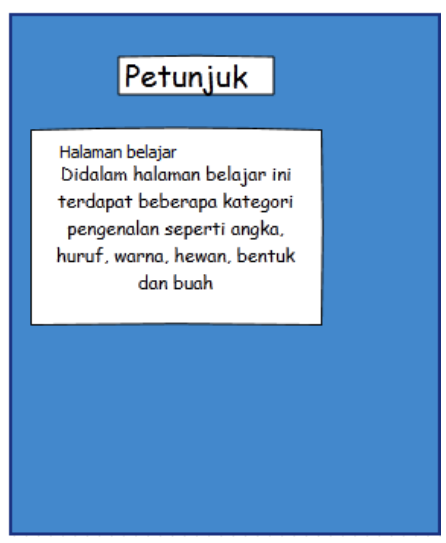

Gambar 9. Rancangan Halaman Petunjuk

Gambar 8 adalah Rancangan halaman bernyanyi pada halaman ini disediakan beberapa pilihan lagu anak-anak yang mudah dihafal dan mudah diikuti gerakannya. Sedangkan gambar 9 adalah halaman petunjuk disediakan untuk menunjukan petunjuk halaman-halaman yang ada.

\subsection{Tahap Implementasi}

Pada gambar 9, terdapat halaman belajar dan bermain hewan, pada fitur belajar siswa dapat melihat bentuk hewan dan mendengarkan suara hewan tersebut, sedangkan untuk menu bermain hewan pada siswa PAUD dapat menebak hewan berdasarkan pertanyaan yang diajukan, 
permainan tersebut dapat melatih kemampuan kognitif siswa dalam menghafal jenis-jenis hewan.
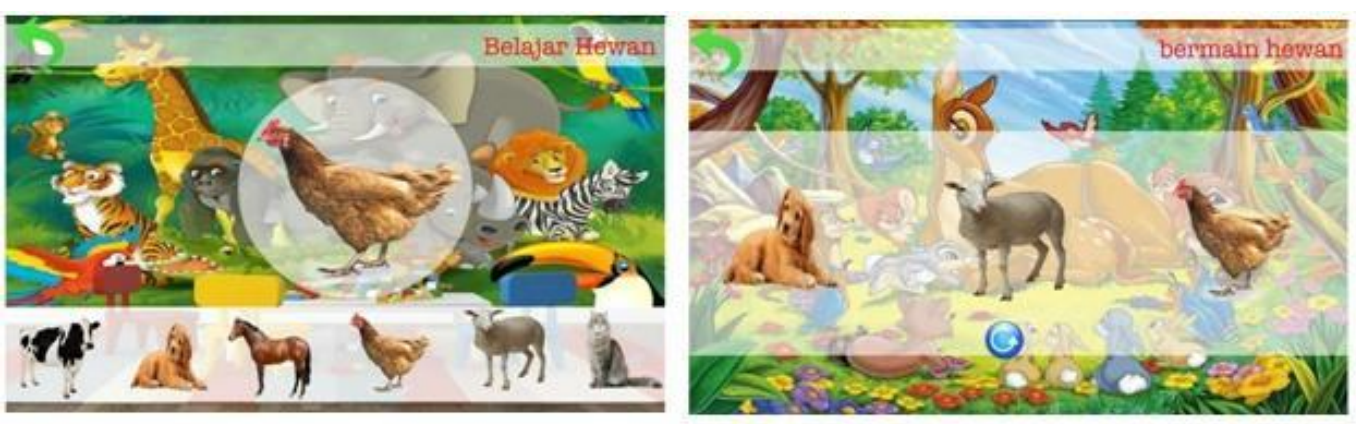

Gambar 9. Tampilan halaman belajar dan bermain hewan
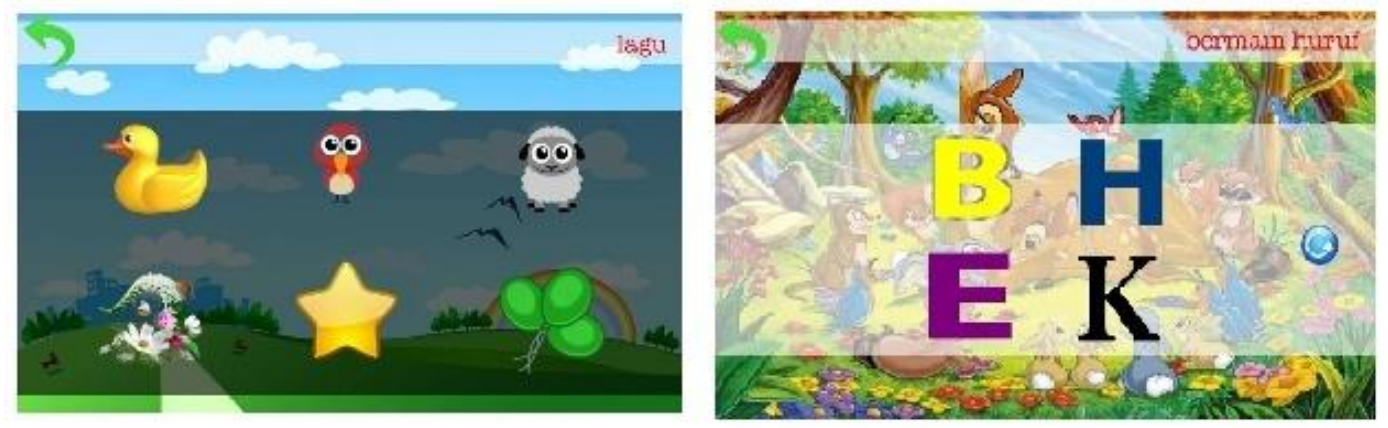

Gambar 10. Tampilan bermain huruf dan lagu.

Pada gambar 10 ditampilkan halaman bermain huruf dan menyanyikan lagu-lagu anak populer seperti potong bebek angsa, burung hantu, balonku dan sebagainya, lagu-lagu tersebut bermanfaat mengasah kemampuan psikomotorik menirukan lagu dan gerakan dari guru. Sedangkan untuk menu bermain huruf pada siswa PAUD diberikan pertanyaan seputar huruf dan siswa dapat memilih jawaban yang benar.

\subsection{Pengujian Aplikasi}

Pengujian ini dimaksudkan untuk menguji aplikasi apakah sudah memenuhi tujuan pembuatan aplikasi atau tidak. Adapun metode pengujian aplikasi ini dengan mencoba aplikasi PAUD oleh beberapa guru dan orang tua siswa. Hasil pilihan yang merepresentasikan kepuasan responden setelah menggunakan aplikasi mobile PAUD dapat dilihat pada Tabel 1:

Tabel 1. Data Uji Aplikasi

\begin{tabular}{|l|c|c|c|c|c|c|}
\hline \multirow{2}{*}{ Aspek penilaian } & \multicolumn{5}{c|}{ Tanggapan } & \multirow{2}{*}{$\%$} \\
\cline { 2 - 7 } & $\mathbf{1}$ & $\mathbf{2}$ & $\mathbf{3}$ & $\mathbf{4}$ & $\mathbf{5}$ & \\
\hline Mode pembelajaran menarik & 4 & 4 & 5 & 5 & 5 & 92 \\
\hline Tampilan aplikasi menarik & 4 & 5 & 5 & 5 & 5 & 96 \\
\hline Mode permainan menarik & 4 & 4 & 4 & 5 & 5 & 88 \\
\hline Audio pada aplikasi menarik & 4 & 4 & 4 & 4 & 5 & 84 \\
\hline Aplikasi mudah digunakan & 4 & 4 & 4 & 5 & 5 & 88 \\
\hline
\end{tabular}




\begin{tabular}{|l|l|l|l|l|l|l|}
\hline Aplikasi cukup memberikan kosakata huruf & 4 & 4 & 5 & 4 & 4 & 84 \\
\hline Aplikasi cukup memberikan pengetahuan tentang angka & 4 & 4 & 5 & 5 & 4 & 88 \\
\hline Aplikasi cukup memberikan pengetahuan tentang hewan & 4 & 4 & 4 & 5 & 4 & 84 \\
\hline Aplikasi cukup memberikan pengetahuan tentang buah & 4 & 4 & 4 & 5 & 4 & 84 \\
\hline Aplikasi sesuai untuk anak usia PAUD & 4 & 4 & 5 & 5 & 5 & 92 \\
\hline $\begin{array}{l}\text { Aplikasi dapat membantu daya pikir (kognitif) anak usia } \\
\text { PAUD }\end{array}$ & 4 & 4 & 5 & 5 & 5 & 92 \\
\hline $\begin{array}{l}\text { Aplikasi dapat membantu daya gerak (psikomotorik) anak } \\
\text { usia PAUD }\end{array}$ & 4 & 4 & 5 & 5 & 5 & 92 \\
\hline
\end{tabular}

Keterangan: $\quad 1=$ sangat tidak setuju; $2=$ tidak setuju; $3=$ tidak tahu $; 4=$ setuju ;

5 = sangat setuju

Pada tabel di atas diperoleh informasi antara lain :

1. Jumlah responden sebanyak 5 orang terdiri dari guru dan wali murid.

2. Untuk aspek mode pembelajaran, tampilan aplikasi, aspek pendukung daya fikir dan daya gerak mendapatkan tanggapan yang cukup tinggi dengan persentasi $>90 \%$, ini menandakan bahwa guru dan wali murid setuju aplikasi ini dapat membantu daya pikir dan gerak anak didiknya.

\section{Kesimpulan}

Berdasarkan hasil pengujian dan implementasi aplikasi mobile untuk siswa paud, dapat disimpulkan sebagai berikut :

1. Aplikasi mobile yang telah dibangun untuk para siswa paud menggunakan android dan basis data mysql sudah dapat digunakan untuk kebutuhan PAUD.

2. Fitur dan konten yang ada berjalan dengan baik.

3. Berdasarkan quesioner yang dibagikan kepada para guru dan orang tua siswa didapatkan hasil bahwa :

a. Aplikasi yang telah dibuat dengan platform android mempermudah penggunaan siswa dalam mengakses konten belajar dan bermain.

b. Konten belajar dan bermain sudah cukup baik untuk membantu mengenalkan nama-nama hewan, buah, angka dan huruf.

c. Aplikasi yang dibangun dapat membantu meningkatkan kemampuan kognitif dan psikomotorik siswa dan dapat mengurangi keterbatasan yang terjadi selama ini.

Saran untuk penelitian selanjutnya sebagai berikut :

1. Konsep pembelajaran dan permainan agar bisa lebih variatif misal dengan bantuan VR (virtual reality) pengenalan hewan, huruf dan sebagainya.

2. Hasil penilaian bisa dijadikan rujukan untuk para guru dalam menilai kompetensi siswanya misal dibantu dengan metode-metode dalam sistem pakar.

3. Aplikasi dapat dinilai tingkat penerimaan usernya dari beberapa data PAUD.

\section{Daftar Pustaka}

[1] S. Murti, Muhibbuddin, and C. Nurmaliah, "Penerapan pembelajaran berbasis praktikum untuk peningkatan kemampuan kognitif dan psikomotorik pada perkuliahan anatomi tumbuhan,” J. Biol. Edukasi, Vol. 6, No. 1, pp 1-8, 2014.

[2] A. Setiawan, "Pengaruh penerapan remote electronic voting system (REVS) terhadap tingkat partisipasi pemilih menggunakan model UTAUT," J. Teknol. Terap., Vol. 3, No. 1, pp 1-6, 2017. 
[3] H. R. Esmaeel, "Apply android studio ( SDK ) tools," Int. J. Adv. Res. Comput. Sci. Softw. Eng., Vol. 05, No. 5, pp 88-93, 2015.

[4] F. Hartanto, H. Selina, Z. H, and S. Fitra, "Pengaruh perkembangan bahasa terhadap perkembangan kognitif anak usia 1-3 tahun," Sari Pediatr., 2011.

[5] S. Balaji, "Waterfall vs v-model vs agile : a comparative study on SDLC," waterfall vs v-model vs agile. a comp. study SDLC," Vol. 2, no. 1, pp. 26-30, 2012. 